\title{
Spark Plasma Sintering of Soft Magnetic Fe-Si-B-P-Cu Nanocrystalline Alloy in the Form of Magnetic Cores
}

\author{
Yan Zhang ${ }^{1, *}$, Parmanand Sharma ${ }^{2}$ and Akihiro Makino ${ }^{2}$ \\ ${ }^{1}$ Graduate School of Engineering, Tohoku University, Sendai 980-8577, Japan \\ ${ }^{2}$ Institute for Materials Research, Tohoku University, Sendai 980-8577, Japan
}

Flakes of $\mathrm{Fe}_{84.3} \mathrm{Si}_{4} \mathrm{~B}_{8} \mathrm{P}_{3} \mathrm{Cu}_{0.7}$ amorphous alloy ribbons with low glass forming ability were consolidated into bulk nanocrystalline specimens (magnetic core shape) with $12 \mathrm{~mm}$ in diameter and $2-5 \mathrm{~mm}$ in height by the spark plasma sintering (SPS) technique. The SPS technique, capable of rapid heating and cooling, enabled us to obtain a densely compacted bulk nanocrystalline material by maintaining the status of amorphous structure or nanocrystalline structure. As a result, high relative density $\sim 91.8-96.1 \%$ and nanocrystalline structure with average grain size below $41 \mathrm{~nm}$ were obtained. The Vickers hardness of the bulk nanocrystalline samples approaches to 1513 , which is 2.0 and 3.2 times of the as-quenched amorphous ribbon and the fully annealed ingot, respectively. These sintered nanocrystalline materials exhibit good soft magnetic properties (saturation magnetic flux density $\sim 1.5-1.68 \mathrm{~T}$, coercivity $\sim 41-120 \mathrm{Am}^{-1}$ ), and can be useful for high magnetic flux density and high frequency applications. [doi:10.2320/matertrans.M2011233]

(Received August 1, 2011; Accepted September 2, 2011; Published October 19, 2011)

Keywords: amorphous alloy, spark plasma sintering, compact, bulk nanocrystalline material, soft magnetic property

\section{Introduction}

Nanocrystalline materials have attracted a lot of attention due to their unique physical and chemical properties, ${ }^{1-8)}$ which are different from the conventional materials. However in some cases, especially the nanocrystalline soft magnetic materials, there is a limitation in the fabrication of bulk products. For commercial applications, mass production of bulk nanocrystalline material is necessary. Considering the recent problems of increased air pollution from vehicles and the demand for energy saving, it is necessary to miniaturize electrical/electronic equipments and improve their efficiencies. Additionally, there is an increasingly urgent requirement to develop excellent soft magnetic materials for high frequency applications such as high frequency transformers for X-ray CT scan, induction heating apparatus, welding machine and communication equipments, choke coils for power conditioner of photovoltaic, wind power generator, fuel cell, inductors for boosting/down converting in hybrid electrical vehicles (HEV), FCV, uninterrupted power supplies (UPS), etc. Currently, ferrite is widely used as a core material for such high frequency applications but it exhibits a low magnetic permeability. Although ferrite core can be shaped with a high degree of freedom by low cost and high productivity, but they exhibit too low saturation magnetization to realize miniaturization. Other compact magnetic powder cores which use binder for electrical insulation between the particles can reduce the eddy current loss but it is at the cost of reduced magnetic flux density. More over such cores have high coercivity over $100 \mathrm{Am}^{-1}$.

The nano-crystalline magnetic materials those are usually obtained after crystallization of amorphous phase in a ribbon/bulk form exhibit high magnetic flux density, high permeability and extremely low coercivity. The key to these excellent magnetic properties is the uniform nano-

*Corresponding author, E-mail: zy-jp@imr.tohoku.ac.jp crystallization of nano-sized $\alpha$-Fe grains from an amorphous or hetro-amorphous phase. Recently, Fe-rich Fe-Si-B-P-Cu nanocrystalline soft magnetic alloys have been developed by Makino's group. ${ }^{9-11)}$ The wide ribbons exhibit high saturation magnetization of $1.82-1.85 \mathrm{~T}$ (at $800 \mathrm{Am}^{-1}$ ) and excellent magnetic softness (low coercivity of 2.6-5.8 $\mathrm{Am}^{-1}$, high permeability of $2.4-2.7 \times 10^{4}$ at $1 \mathrm{kHz}$ and small saturation magnetostriction of $2.3-2.4 \times 10^{-6}$ ) along with high electrical resistivity $(0.67-0.74$ micro-ohm meter) can result in superior high frequency characteristics. ${ }^{12)}$ However, because of low glass forming ability without a super-cooled liquid region, it is not possible to realize fabrication of $\mathrm{Fe}$ rich $\mathrm{Fe}-\mathrm{Si}-\mathrm{B}-\mathrm{P}-\mathrm{Cu}$ based bulk alloy by the ordinary copper mold casting method, at least by the existing rapid cooling technique level of support. Therefore, improved processing technologies for bulk core materials are required.

Spark plasma sintering (SPS) technique has recently been attracting much attention as a new solidification molding technique. ${ }^{13-19)}$ The SPS technique can prevent grain growth during compaction and facilitate formation of bulk material by maintaining the amorphous or nanocrystalline structure. In view of the excellent magnetic properties of $\mathrm{Fe}-\mathrm{Si}-\mathrm{B}-\mathrm{P}-\mathrm{Cu}$ alloy ribbons and the absence any report on the formation of bulk cores, here we attempted to make bulk magnetic cores of $\mathrm{Fe}_{84.3} \mathrm{Si}_{4} \mathrm{~B}_{8} \mathrm{P}_{3} \mathrm{Cu}_{0.7}$ by SPS technique. Effect of sintering temperature on the density, grain size and magnetic properties are studied. Mechanical properties of the sintered cores are also investigated in order make sure about the robustness.

\section{Experimental Procedure}

$\mathrm{Fe}_{84.3} \mathrm{Si}_{4} \mathrm{~B}_{8} \mathrm{P}_{3} \mathrm{Cu}_{0.7}$ alloy ingots were produced by highfrequency induction mixtures of $\mathrm{Fe}(99.98$ mass \%) and $\mathrm{Cu}$ (99.99 mass\%), pre-melted Fe-P (99.9 mass\%), pure metalloid of crystal Si (99.999 mass\%) and crystal B (99.5 mass\%) under a high purity argon atmosphere after evacuation up to $10^{-3} \mathrm{~Pa}$. The melt was then subjected to a single-roller melt spinner to prepare amorphous ribbons of approximately 5- 
$6 \mathrm{~mm}$ in width and $20 \mu \mathrm{m}$ in thickness at room temperature. For the purpose of compaction by SPS, ribbons were cut into $1-2 \mathrm{~mm}$ in length in order to increase the densification rate. The ribbon flakes were pre-compacted and then sintered in vacuum to form disk-like samples using a DR.SINTER(R) SPS-3.20MK-IV machine. For the SPS process, ribbon flakes were compacted in a tungsten carbide die of $\sim 12 \mathrm{~mm}$ in diameter by two punch rods, at a heating rate of $0.83 \mathrm{Ks}^{-1}$ under an applied stress of $600 \mathrm{MPa}$. The thermal stability was determined by differential scanning calorimetry (DSC) at a heating rate of $0.67 \mathrm{Ks}^{-1}$ under an argon flowing atmosphere. $\mathrm{X}$-ray diffraction (XRD) with $\mathrm{Cu} \mathrm{K} \alpha$ radiation was used to explore on nano-crystallization behaviors. Grain size of as-sintered samples was estimated from the transmission electron microscopy (TEM) image and also calculated from the XRD patterns by using Scherrer equation. For mechanical properties, Vickers hardness tests were performed under a load of 2.94 N. Saturation magnetization $\left(M_{\mathrm{s}}\right)$ and coercivity $\left(H_{\mathrm{c}}\right)$ were measured by applying a maximum inplane magnetic field of $800 \mathrm{kAm}^{-1}$ by vibrating sample magnetometer and $0.8,2,4 \mathrm{kAm}^{-1}$ by a DC B-H loop tracer. The density was measured by the Archimedean method in n-tridecane.

\section{Results and Discussion}

At first, crystallization behaviors of $\mathrm{Fe}_{84.3} \mathrm{Si}_{4} \mathrm{~B}_{8} \mathrm{P}_{3} \mathrm{Cu}_{0.7}$ amorphous ribbon were studied. This is especially important to decide the sinterning temperature $\left(T_{\mathrm{s}}\right)$ during compaction by SPS. Figure 1 shows the DSC curves of as quenched $\mathrm{Fe}_{84.3} \mathrm{Si}_{4} \mathrm{~B}_{8} \mathrm{P}_{3} \mathrm{Cu}_{0.7}$ amorphous ribbons along with the ribbons sintered at different temperatures. The heating rate was constant $\sim 0.67 \mathrm{Ks}^{-1}$ in all the DSC measurements. First and second crystallizations of the as-quenched amorphous ribbons occur at 675 and $831 \mathrm{~K}$. The absence of supper-cooled liquid region i.e. an endothermic reaction before onset of first crystallization can be noticed. This is an indication of low glass forming ability of $\mathrm{Fe}_{84.3} \mathrm{Si}_{4} \mathrm{~B}_{8} \mathrm{P}_{3} \mathrm{Cu}_{0.7}$ alloy. The DSC curve of as quenched ribbon suggests that the sintering of ribbons by SPS below $675 \mathrm{~K}$ should not result in crystallization. However the DSC measurment performed on the sample sintered at $T_{\mathrm{s}} \sim 613 \mathrm{~K}$ (Fig. 1) showed a significant decrease in the intensity of first crystallization peak, indicating partial crystallization. The first crystallization peak in DSC was found to disappear totally when the sintering temperature is $\sim 679 \mathrm{~K}$ or above (Fig. 1 ).

Figure 2 shows the XRD patterns of as-quenched ribbons along with the bulk samples sintered by SPS at different $T_{\mathrm{s}} \sim 613$ to $900 \mathrm{~K}$. As expected, a compeletly X-ray amorphous phase is noticed for the as quenched ribbons. Sintering at $T_{\mathrm{s}} \sim 613 \mathrm{~K}$, result in a weak peak superimposed on a broad halow, indicating a minor crystallization. This peak position mataches with the $\alpha$-Fe phase, suggesting the samples sintered at $613 \mathrm{~K}$ are composed minor $\alpha$-Fe nanograins that are surrounded by the amorphous matrix. This minor crystallization is also consistent with our DSC curve which showed a significant decrease in peak height in comparision to the DSC of as quenched ribbons. The X-ray peak intensity of $\alpha$-Fe phase increases with increasing $T_{\mathrm{s}}$. In addition to $\alpha$-Fe phase peak, sintering above $T_{\mathrm{s}} \sim 679 \mathrm{~K}$

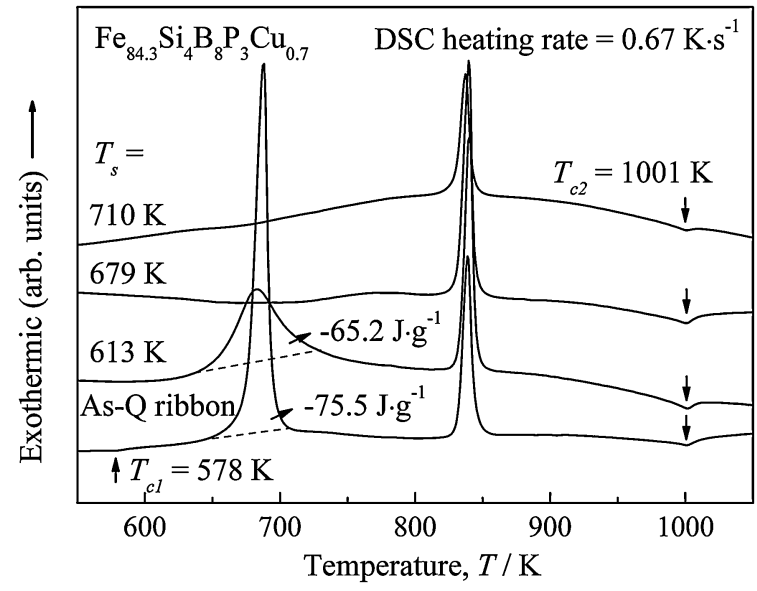

Fig. 1 DSC curves for as-quenched $\mathrm{Fe}_{84.3} \mathrm{Si}_{4} \mathrm{~B}_{8} \mathrm{P}_{3} \mathrm{Cu}_{0.7}$ ribbon, and spark plasma sintered $\mathrm{Fe}_{84.3} \mathrm{Si}_{4} \mathrm{~B}_{8} \mathrm{P}_{3} \mathrm{Cu}_{0.7}$ magnetic cores sintered at different $T_{\mathrm{s}}$ (heating rate $\sim 0.83 \mathrm{Ks}^{-1}$ ).

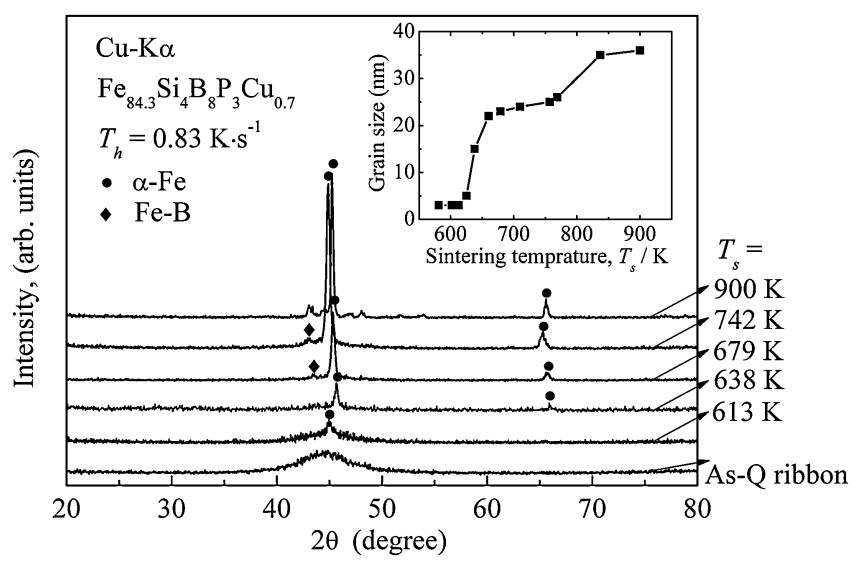

Fig. 2 XRD patterns of as-quenched $\mathrm{Fe}_{84.3} \mathrm{Si}_{4} \mathrm{~B}_{8} \mathrm{P}_{3} \mathrm{Cu}_{0.7}$ ribbon and spark plasma sintered $\mathrm{Fe}_{84.3} \mathrm{Si}_{4} \mathrm{~B}_{8} \mathrm{P}_{3} \mathrm{Cu}_{0.7}$ magnetic cores sintered at different $T_{\mathrm{s}}$ (heating rate $\sim 0.83 \mathrm{Ks}^{-1}$ ). Inset shows the variation in grain size (calculated from XRD patterns) with $T_{\mathrm{s}}$.

leads to other peaks, which correspond to Fe-B related phases (Fig. 2). On carefull examination of $\alpha$-Fe peak width, it can be noticed that the peak width decreases with an increase in $T_{\mathrm{s}}$. As the X-ray peak width is related to the grain size, therefore we can estimate the variation in grain size with $T_{\mathrm{s}}$ by using Scherrer's formula (inset to Fig. 2). When the $T_{\mathrm{s}}$ is below $625 \mathrm{~K}$, the grain size is $<3 \mathrm{~nm}$. With increasing $T_{\mathrm{s}}$, the grain size of $\alpha$-Fe increases rapidly and remains nearly constant $(\sim 25 \mathrm{~nm})$ in the $T_{\mathrm{s}}$ range of $\sim 638-769 \mathrm{~K}$. Further increase in $T_{\mathrm{s}}$ again results in an increase in $\alpha$-Fe grain size.

Usually, the grain size obtained from the XRD measurements is under estimated and also the information about the grain size distribution is unknown, therefore we have performed TEM measurements on selected samples. Figure 3 shows the TEM bright field images and the selected area electron diffraction (SAED) patterns of the samples sintered at 613,638 and $679 \mathrm{~K}$. As expected from the DSC and XRD measurments (Fig. 1 and 2), the TEM investigation also showed majority of amorphous phase for the sample sintered at $T_{\mathrm{s}} \sim 613 \mathrm{~K}$ [Fig. 3(a)]. Precipitation of $\alpha$-Fe grains of size $\sim 25 \mathrm{~nm}$ is also noticed in the amorphous matrix. The volume 

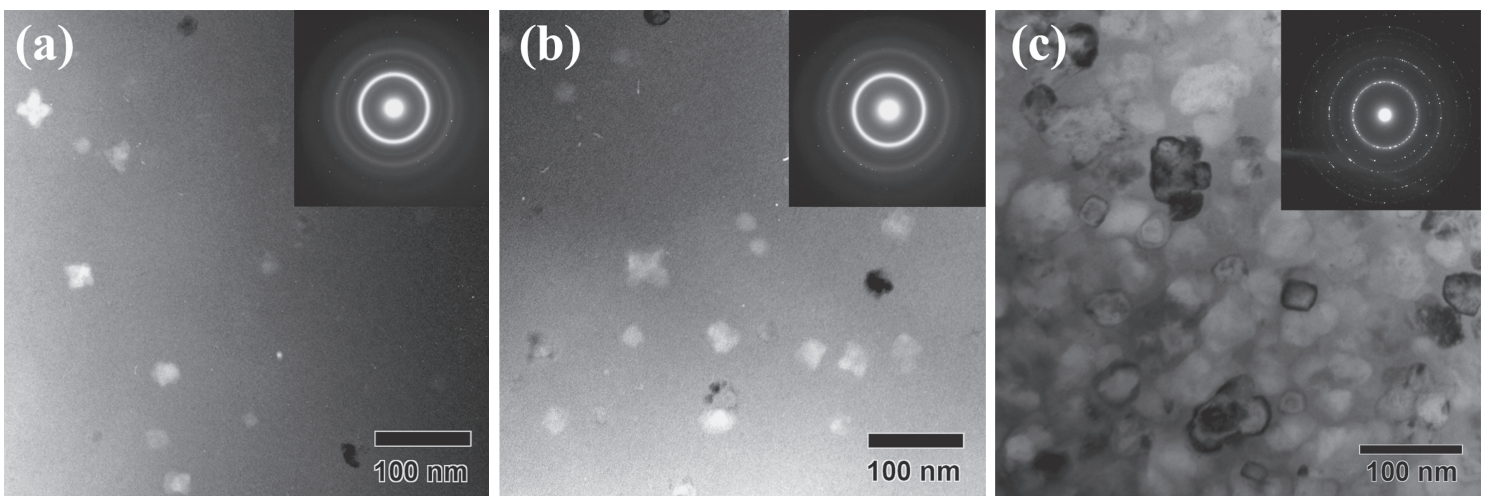

Fig. 3 Bright field TEM images and SAED patterns of $\mathrm{Fe}_{84.3} \mathrm{Si}_{4} \mathrm{~B}_{8} \mathrm{P}_{3} \mathrm{Cu}_{0.7}$ magnetic cores sintered (heating rate $\sim 0.83 \mathrm{Ks}^{-1}$ ) at, (a) $T_{\mathrm{s}}=613 \mathrm{~K}$, (b) $T_{\mathrm{s}}=638 \mathrm{~K}$, (c) $T_{\mathrm{s}}=679 \mathrm{~K}$.

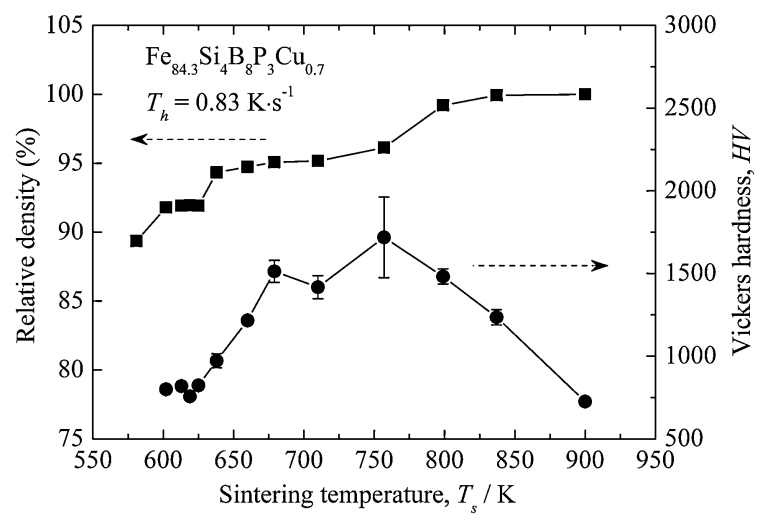

Fig. 4 The $T_{\mathrm{s}}$ dependence of relative density (compared to $7.46 \mathrm{gcm}^{-3}$ of the as-annealed nanocrystalline ribbon) and Vickers hardness of the samples sintered at a heating rate of $0.83 \mathrm{Ks}^{-1}$.

fraction of $\alpha$-Fe grains in the amorphous matrix increases significantly without a much increase in grain size on sintering of ribbons at $T_{\mathrm{s}} \sim 638 \mathrm{~K}$ [Fig. 3(b)]. Fully nanocrystalline bulk samples of $\mathrm{Fe}_{84.3} \mathrm{Si}_{4} \mathrm{~B}_{8} \mathrm{P}_{3} \mathrm{Cu}_{0.7}$ alloy were obtained on sintering at $679 \mathrm{~K}$. From Fig. 3(c), it can be noticed that the grain size is quite uniform through out the sample, and the average grain size is $\sim 41 \mathrm{~nm}$. A careful analysis of SAED pattern and the lattice images of the sintered material only revealed presence of $\alpha$-Fe grains which are separated by a very thin amorphous layer. Thin amorphous layer seems to help in the suppression of grain growth during sintering. Although minor peaks of $\mathrm{Fe}-\mathrm{B}$ related phases were noticed in the XRD pattern (Fig. 2), but we could not observe such phases in our TEM analysis, this may be because TEM observations are very much localized in comparison to XRD.

In order to make robust cores by sintering process, the density of the sintered material and its mechanical properties are very important. Therefore we have investigated the effect of sintering temperature on the density and mechanical properties of nanocrystalline $\mathrm{Fe}_{84.3} \mathrm{Si}_{4} \mathrm{~B}_{8} \mathrm{P}_{3} \mathrm{Cu}_{0.7}$ alloy cores and are shown in Fig. 4. The density of present SPS samples varies from $\sim 89.4-99.9 \%$ of the density of as annealed nano-crystalline $\mathrm{Fe}_{84.3} \mathrm{Si}_{4} \mathrm{~B}_{8} \mathrm{P}_{3} \mathrm{Cu}_{0.7}$ alloy ribbons (density of ribbons $\sim 7.46 \mathrm{gcm}^{3}$ ). As expected, the density of the SPS samples increases slowly with an increase in sintering temperature and reaches close to $100 \%$ at $T_{\mathrm{s}} \sim 800 \mathrm{~K}$. However, the Vickers hardness $(H V)$ shows a peak at $T_{\mathrm{s}} \sim 750 \mathrm{~K}$. The increase in $H V$ with increasing $T_{\mathrm{s}}$ can be understood based on the density of sintered sample ie. $H V$ increases with the increase in density, but a decrease in hardness with increasing $T_{\mathrm{s}}$ for nearly constant density ( $\sim 99 \%$ ) samples is related to the micro-structure. It is reported that nanocrystalline materials exhibit higher hardness than their bulk counter parts. ${ }^{20,21)}$ This is known as HallPetch effect. If we notice the variation in grain size with $T_{\mathrm{s}}$ (Fig. 2 inset), the grain size is less than $3 \mathrm{~nm}$ for $T_{\mathrm{s}}<625 \mathrm{~K}$, and it increases rapidly and again remain constant for $T_{\mathrm{s}} \sim 650-750 \mathrm{~K}$, but it again increases with a further increase in $T_{\mathrm{s}}$. The $T_{\mathrm{s}} \sim 750 \mathrm{~K}$ is the temperature where hardness is maximum, therefore we believe the decrease in hardness above this temperature is due to grain grwoth (Hall-Petch effect). Although decrease in $H V$ below $T_{\mathrm{s}} \sim 750 \mathrm{~K}$ is mainly due to low density, but based on the reduced grain size, contribution from the inverse Hall-Petch effect can not be ignored. It is too be noted that the present bulk nanocrystalline samples sintered at $T_{\mathrm{s}} \sim 679 \mathrm{~K}$ exhibit $H V \sim 1513$, which is $\sim 2.0$ times of as quenched ribbons and $\sim 3.2$ times of fully crystalline (annealed) alloy of same composition.

For measurments of magnetic properties such as saturation magnetization, and coercivity, the samples were processed in the form of toroid. Toroidal shape of the sample is especially important to eliminate the effects of demagnetization related the geometry of the sample. Figure 5 show the $T_{\mathrm{s}}$ dependence of $M_{\mathrm{S}}$ and $H_{\mathrm{c}}$ of $\mathrm{Fe}_{84.3} \mathrm{Si}_{4} \mathrm{~B}_{8} \mathrm{P}_{3} \mathrm{Cu}_{0.7}$ nanocrystalline bulk samples sintered at a heating rate of $0.83 \mathrm{Ks}^{-1}$. The $M_{\mathrm{s}}$ of the samples sintered below $638 \mathrm{~K}$ is less than $1.5 \mathrm{~T}$, and this is basically because of amorphous structure. Usually $M_{\mathrm{s}}$ is low for amorphous state in comparison to the fully crystalline state, even for the same alloy composition. With a further increase of $T_{\mathrm{s}}$ until $769 \mathrm{~K}$, the $M_{\mathrm{s}}$ increased from 1.64 to $1.70 \mathrm{~T}$ due to precipitation of high density of a large number of nanocrystalline $\alpha$-Fe and minor Fe-B grains (which have higher $M_{\mathrm{S}}$ than the amorphous phase) in an amorphous matrix. The $M_{\mathrm{s}}$ of fully crystalline samples $\left(T_{\mathrm{s}} \sim 900 \mathrm{~K}\right)$ approaches to $\sim 1.8 \mathrm{~T}$.

The $H_{\mathrm{c}}$ of samples sintered at $T_{\mathrm{s}} \sim 600$ to $900 \mathrm{~K}$ is found to increase with an increase in $T_{\mathrm{s}}$ (Fig. 5). Below $T_{\mathrm{s}} \sim 638 \mathrm{~K}$, the structure of the sample is amorphous, but the $H_{\mathrm{c}}$ is much higher $\left(\sim 50 \mathrm{Am}^{-1}\right)$ than the $H_{\mathrm{c}}$ of amorphous ribbons 


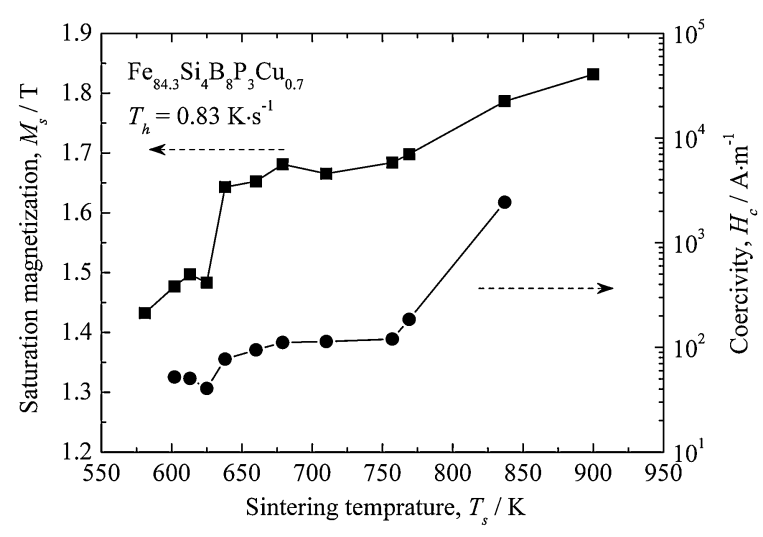

Fig. 5 The $T_{\mathrm{s}}$ dependences of $M_{\mathrm{s}}$ and $H_{\mathrm{c}}$ of $\mathrm{Fe}_{84.3} \mathrm{Si}_{4} \mathrm{~B}_{8} \mathrm{P}_{3} \mathrm{Cu}_{0.7}$ nanocrystalline sintered magnetic cores.

$\left(\sim 12 \mathrm{Am}^{-1}\right)$. We believe this is due to porous structure (because of low density) of the samples in which pores may act as pinning centers and result in an increase in $H_{\mathrm{c}}$. On increasing $T_{\mathrm{s}}$, density of precipitated nano-sized $\alpha$-Fe grains (which has higher magnetocrystalline anisotropy than the amorphous phase) increases in the amorphous matrix, but the structure of the samples still contain large number of pores. The large distance between $\alpha$-Fe grains (larger than the exchange-coupled length), and the porous structure result in a rapid increase in $H_{\mathrm{c}}$. Around $T_{\mathrm{s}} \sim 679 \mathrm{~K}$, the density approaches to $\sim 96 \%$ (Fig. 4) and the increase in $H_{\mathrm{c}}$ with a further increase in $T_{\mathrm{s}}$ also slows down (Fig. 5). Still the $H_{\mathrm{c}}$ $\left(\sim 115 \mathrm{Am}^{-1}\right)$ is much larger than the annealed ribbons. Probably, high value of $H_{\mathrm{c}}$ for sintered samples is due to large grain size $(\sim 41 \mathrm{~nm})$ of $\alpha$-Fe compared to annealed ribbons $(\sim 15 \mathrm{~nm})$. It is well known that the magnetic anisotropy density is proportional to the sixth power of grain size, ${ }^{22)}$ the $H_{\mathrm{c}}$, which is caused by anisotropy, will decrease dramatically with decreasing grain size. When the grain size becomes very small, the exchange effects become so strong that the magnetization of each grain is no longer determined by its crystallographic anisotropy, and the domain is formed by the combination of many grains with exchanged magnetization in the same direction. Therefore, it is necessary to control the grain size of $\alpha-\mathrm{Fe}$ in addition to a uniform and narrow size distribution. In case of sintered samples, there seems a competition between grain size and density. Improvement in density results in an increase in grain size.

\section{Conclusions}

We have made a first attempt to fabricate bulk soft magnetic cores of low glass forming $\mathrm{Fe}_{84.3} \mathrm{Si}_{4} \mathrm{~B}_{8} \mathrm{P}_{3} \mathrm{Cu}_{0.7}$ alloy by SPS processing. Nanocrystalline $\mathrm{Fe}_{84.3} \mathrm{Si}_{4} \mathrm{~B}_{8} \mathrm{P}_{3} \mathrm{Cu}_{0.7}$ alloy in ribbon form exhibit excellent soft magnetic properties, which ensure its use in high magnetic flux density and high frequency applications. We have succeeded in fabrication of bulk nanocrystalline soft magnetic cores with material density close to $96 \%$. High Vickers hardness $\sim 1513$ of the present magnetic cores ensure their mechanical robustness. The sintered magnetic cores exhibit high magnetic flux density $\sim 1.50-1.68 \mathrm{~T}$ along with low coercivity $\sim 41-$ $120 \mathrm{Am}^{-1}$. The coercivity of the bulk samples is higher than the coercivity of the nano-crystalline ribbons, and it is due to low density and slightly larger grain size $(\sim 41 \mathrm{~nm})$. Our results showed that the improvement in density results in an increase in grain size. Further improvement in the magnetic properties of $\mathrm{Fe}_{84.3} \mathrm{Si}_{4} \mathrm{~B}_{8} \mathrm{P}_{3} \mathrm{Cu}_{0.7}$ alloy may be possible by increasing the heating rate during SPS sintering. Increased heating rate may inhibit grain growth and lead to the grain size similar to nanocrystalline ribbons ( $\sim 15$ to $20 \mathrm{~nm}$ ).

\section{Acknowledgement}

Authors thank Dr. Sangmin Lee for his support during SPS processing of samples. This work was supported by Global COE Program "Materials Integration (International Center of Education and Research), Tohoku University," MEXT, Japan.

\section{REFERENCES}

1) Y. Yoshizawa, S. Oguma and K. Yamauchi: J. Appl. Phys. 64 (1988) 6044-6046.

2) K. Suzuki, A. Makino, N. Kataoka, A. Inoue and T. Masumoto: Mater. Trans. 32 (1991) 93-102.

3) A. Makino and T. Bitoh: J. Appl. Phys. 93 (2003) 6522-6524.

4) M. Koizumi, Y. Sakka, K. Chujo and K. Niihara: Advanced Technology of Nano-materials, (CMC, Tokyo, 2001) pp. 243-278.

5) Charles P. Poole, Jr. and Frank J. Owens: Introduction to Nanotechnology, (Wiley-Interscience, New Jersey, 2003) pp. 165-186.

6) A. Inoue: Advanced technology and application of nanometals, (CMC, Tokyo, 2008) pp. 241-299.

7) A. Makino, T. Bitoh, A. Inoue and T. Masumoto: Scr. Mater. 48 (2003) 869-874.

8) A. Makino, M. Bingo, T. Teruo, K. Yubuta and A. Inoue: J. Appl. Phys. 101 (2007) 09N117-1-09N117-3.

9) A. Makino, H. Men, K. Yubuta and T. Kubota: J. Appl. Phys. 105 (2009) 013922-1-013922-4.

10) A. Makino, H. Men, T. Kubota, K. Yubuta and A. Inoue: IEEE Trans. Mag. 45 (2009) 4302-4305.

11) Men He, L. Y. Cui, T. Kubota, K. Yubuta, A. Makino and A. Inoue: Mater. Trans. 50 (2009) 1330-1333.

12) A. Makino, T. Kubota, K. Yubuta, A. Inoue, A. Urata, H. Matsumoto and S. Yoshida: J. Appl. Phys. 109 (2011) 07A302-1-07A0302-2.

13) B. Shen, H. Kimura, A. Inoue, M. Omori and A. Okubo: Mater. Trans. 43 (2002) 1961-1965.

14) B. Shen, A. Inoue, H. Kimura, M. Omori and A. Okubo: Mater. Sci. Eng. A 375 (2004) 666-671.

15) S. Ishihara, W. Zhang, H. Kimura, M. Omori and A. Inoue: Mater. Trans. 44 (2003) 138-143.

16) T. S. Kim, J. K. Lee, H. J. Kim and J. C. Bae: Mater. Sci. Eng. A 402 (2005) 228-233.

17) T. Isobe, K. Daimon, T. Sato, T. Matsubara, Y. Hikichi and T. Ota: Ceram. Int. 34 (2008) 213-217.

18) D. Roy, S. Kumari, R. Mitra and I. Manna: Intermetallics 15 (2007) 1595-1605.

19) V. Mamedov: Pow. Metall. 45 (2002) 322-328.

20) E. O. Hall: Proc. Phys. Soc. B 64 (1951) 747-753.

21) N. J. Petch: J. Iron Steel Inst. 174 (1953) 25-28.

22) G. Herzer: IEEE Trans. Mag. 26 (1990) 1397-1402. 